\title{
A case of small bowel metastasis from spinal Ewing sarcoma causing intussusception in an adult female
}

\author{
Qing Ting Tan ${ }^{1 *}$, Jin Yao Teo², Syed Salahuddin Ahmed $^{3}$ and Alexander Yaw Fui Chung ${ }^{2}$
}

\begin{abstract}
Background: Ewing sarcomas are highly aggressive malignant tumours occurring predominantly in the long bones of the extremities in children and young adults. About $20 \%$ of patients will present with metastases at diagnosis with the commonest sites being the lungs, bone and bone marrow. Cases of primary small bowel Ewing sarcomas have been described but are nonetheless exceedingly rare, even more so cases of metastasis to the small bowel.

Case Presentation: We describe a case of vertebral Ewing sarcoma in a 44 year-old female which metastasized to the jejunum causing intussusception.

Conclusions: Ewing's sarcoma is highly aggressive and presence of metastases, overt or subclinical, is thought to be present in almost all patients at diagnosis. As evidenced by our patient, metastatic disease can progress rapidly to cause further complications and confer a poorer survival. The possibility of metastasis, no matter how rare or unlikely the site is, should be considered and actively investigated to expedite treatment of the primary disease.
\end{abstract}

Keywords: Ewing sarcoma, Adult, Metastasis, Small bowel, Intestinal, Obstruction, Intussusception

\section{Background}

Ewing sarcomas are rare small round cell tumours that arise predominantly in children and young adults with a slight male predilection $[1,4,7]$. Ewing sarcoma most often arises in the mid-shaft or diaphysis of the long bones of the extremities with the spine making up $8 \%$ of primary sites [2]. Approximately, $80 \%$ of patients present with clinically localized disease although it is surmised that subclinical metastatic disease is present in almost all patients due to high relapse rates of 80 to $90 \%$ in patients undergoing local therapy alone [3]. Metastases are mostly found in the lungs, bone and bone marrow [4]. Eight cases of primary small bowel Ewing sarcoma have been reported [8-10, 14]. One such case occurred in an 18-year-old male which was complicated by intussusception as well [9]. Reports of metastasis of Ewing sarcoma to the small bowel are even fewer and far between. Capitini reported a case of left femur Ewing

\footnotetext{
* Correspondence: tan.qing.ting@kkh.com.sg

1 Department of General Surgery, Singapore General Hospital, Outram Road,

Singapore 169608, Singapore

Full list of author information is available at the end of the article
}

sarcoma metastasizing to the brain and small intestine after allogenic stem cell transplantation [13].

\section{Case presentation}

A previously well 44-year-old female presented with acute lower limb numbness and weakness of 1-day duration. Prior to this, she suffered from back pain for 2 weeks that gradually progressed to pain in both hips as well. There were no complaints of urinary or bowel incontinence. She did not experience any abdominal pain, distension, vomiting or constipation.

On examination, the patient had decreased sensation and power in the bilateral lower limbs and up-going plantar reflexes. Abdominal examination revealed no mass or distension. Bowel sounds were active. Anal tone was intact on digital rectal examination.

Magnetic resonance imaging of her thoracic and lumbar spine with $10 \mathrm{ml}$ intravenous Magnevist showed abnormal marrow replacement affecting the 11th thoracic vertebral body associated with enhancement causing compression of the spinal cord (Fig. 1). The initial impression was spine metastases from unknown primary causing spinal cord compression. The patient underwent excision of thoracic 


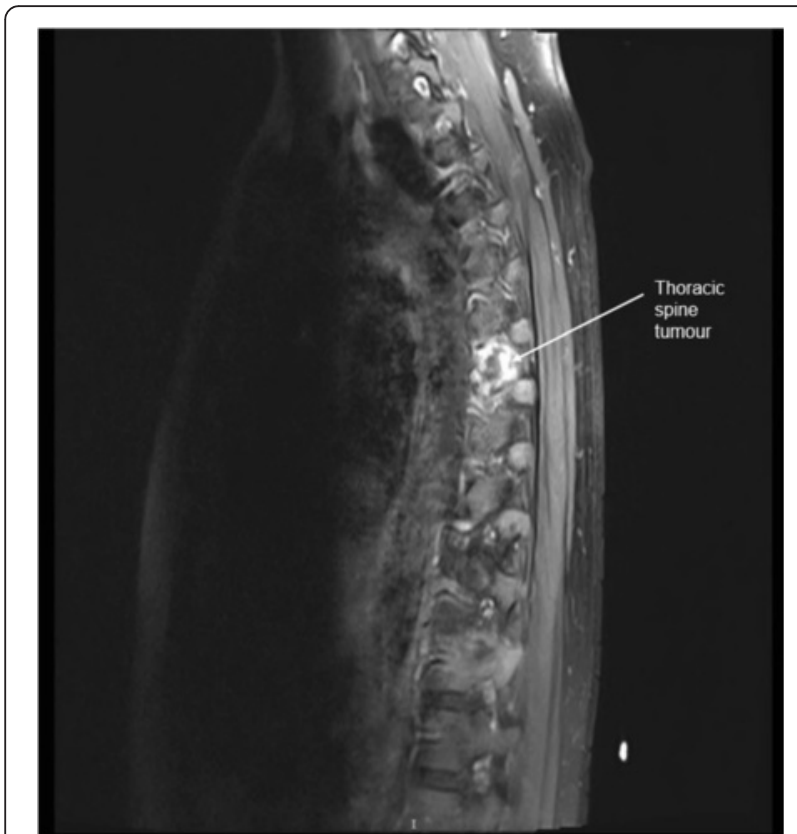

Fig. $1 \mathrm{MRI}$ spine showing abnormal enhancement of the thoracic vertebra with spinal cord compression

spine tumour, decompression laminectomy and fixation the following day. A computed tomography (CT) scan of her thorax and abdomen with $80 \mathrm{ml}$ intravenous Omnipaque 350 was performed 2 days after surgery to look for a primary malignancy. A 2-cm liver lesion (Fig. 2) was detected along with an indeterminate $0.3-\mathrm{cm}$ left pulmonary nodule and a single enlarged $1.3-\mathrm{cm}$ para-aortic lymph node. The small and large bowels were normal (Fig. 3). Immunohistology of the vertebral tumour revealed epidural Ewing sarcoma. Molecular testing detected presence of $\mathrm{t}(11 ; 22)(\mathrm{q} 24 ; \mathrm{q} 12)$ translocation further confirming the diagnosis of Ewing sarcoma.

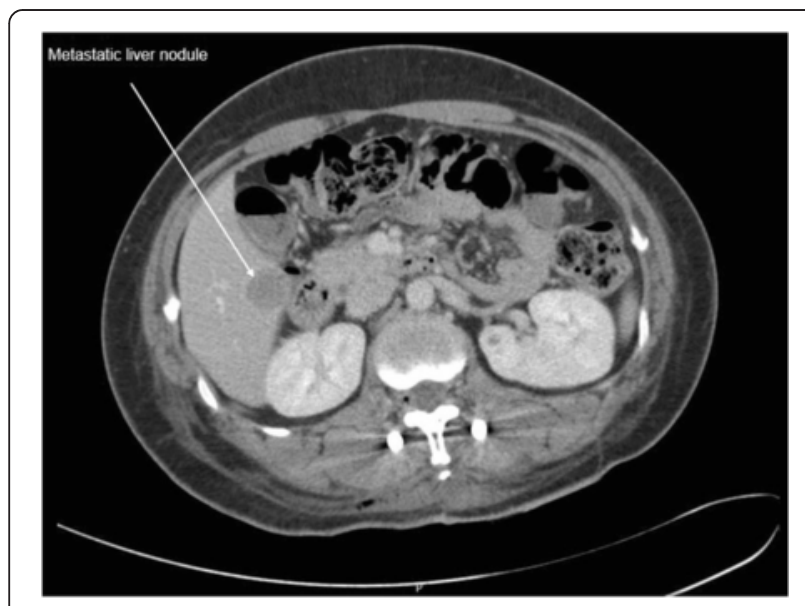

Fig. 2 Liver metastatic nodule on initial CT

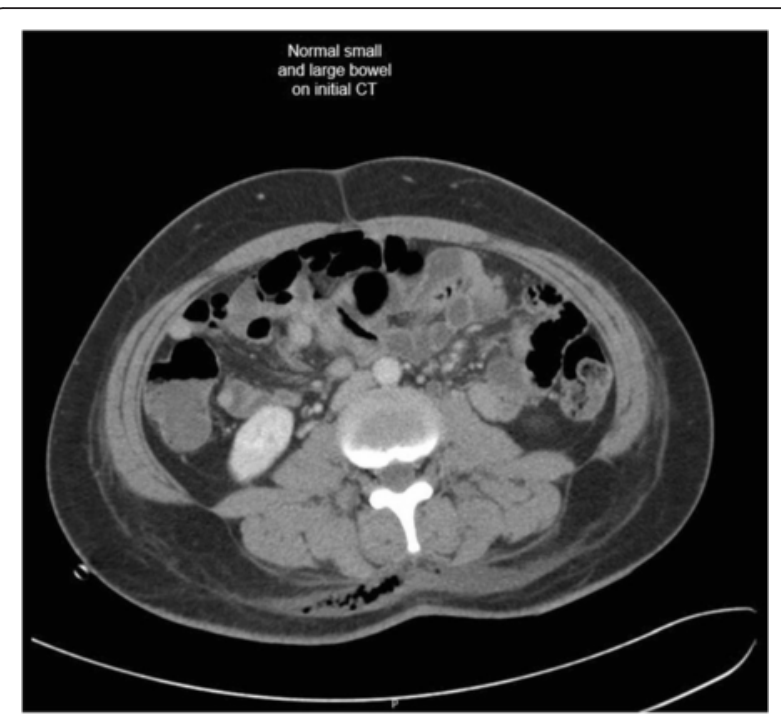

Fig. 3 Normal bowel on initial CT

The patient was planned for chemotherapy but, 3 weeks after her spine surgery, she developed symptoms of intestinal obstruction with persistent vomiting, intermittent upper abdominal pain and distension. A repeat CT scan showed multiple new lytic lesions in the vertebrae, right iliac bone and right femur, increase in size and number of liver nodules (Fig. 4) and para-aortic lymphadenopathy. It also showed new findings of small bowel dilatation secondary to an entero-enteric intussusception (Fig. 5). An emergent laparotomy was performed and jejunal-jejunal intussusception was found (Fig. 6) with a 5 -cm tumour forming the lead point (Fig. 7). There were no other lesions in the small bowel and colon. The affected segment of the small bowel was resected with primary anastomosis. Histopathological examination of the resected small bowel tumour confirmed metastatic Ewing sarcoma, morphologically similar to the spinal tumour (Figs. 8 and 9).The entire panel of immunochemical stains including CD99,

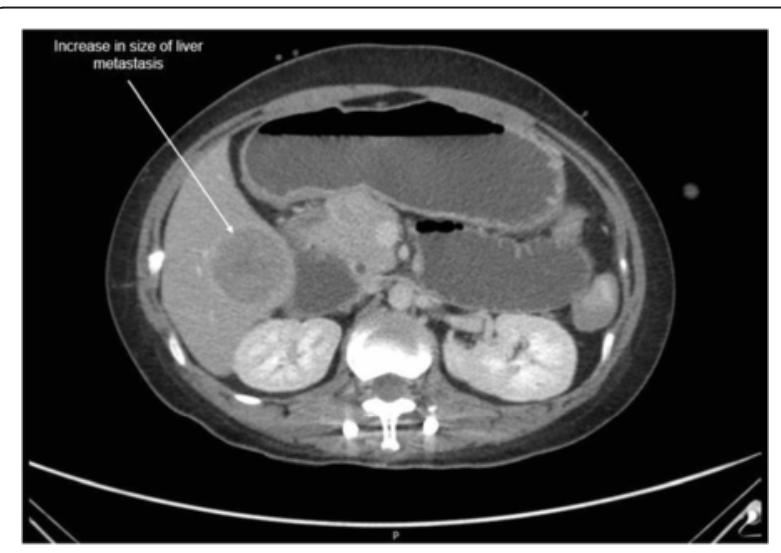

Fig. 4 Increase in size of metastatic liver nodule on subsequent CT 


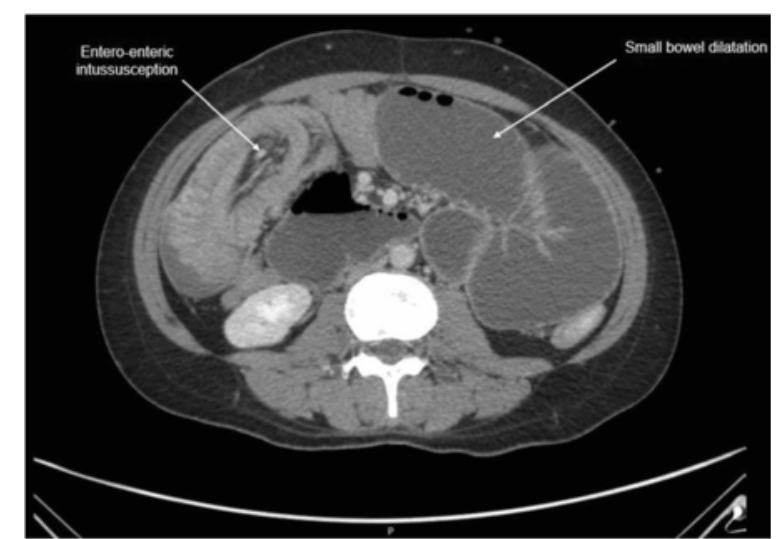

Fig. 5 New development of entero-enteric intussusception and small bowel dilatation on subsequent $C T$

synaptophysin, chromogranin, MNF-116, AE1/AE3, epithelial membrane antigen (EMA), CD34, HMB-45,desmin and S100 showed similar results in both the vertebral as well as the small bowel tumour (Figs. 10, 11, 12 and 13).

The patient made an uneventful recovery from surgery and was started on palliative chemotherapy. She eventually succumbed to progressive metastatic disease 16 months after her initial diagnosis.

\section{Discussion}

The Ewing sarcoma family of tumors (ESFT) consists of Ewing sarcoma, peripheral primitive neuroectodermal tumor (PNET), extraosseous Ewing sarcoma (EES), and

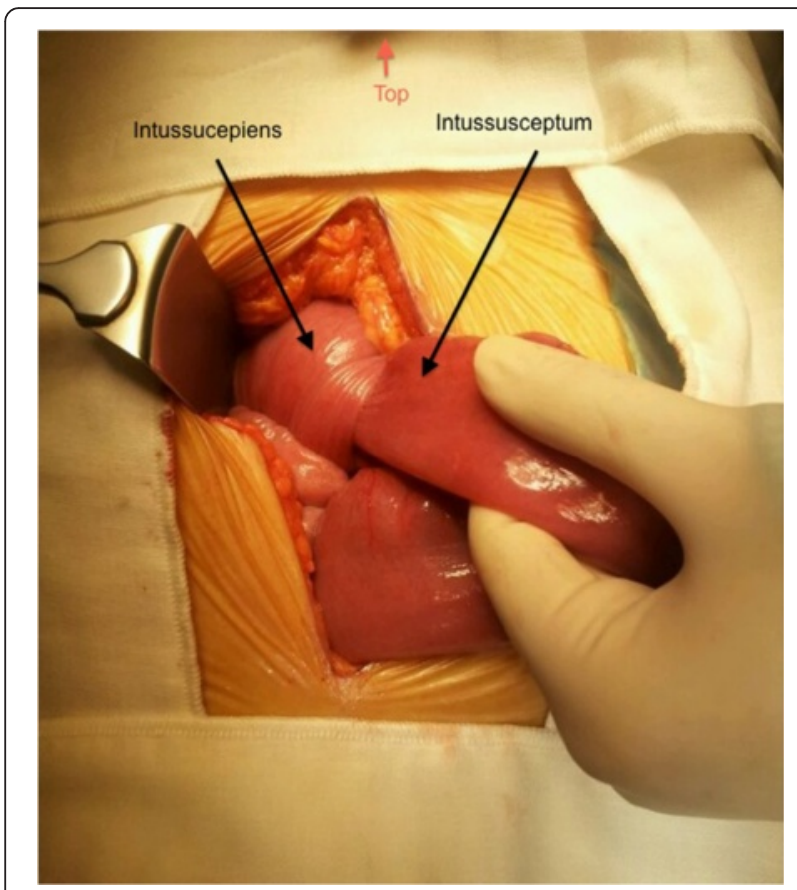

Fig. 6 Intra-operative findings of jejunal-jejunal intussusception

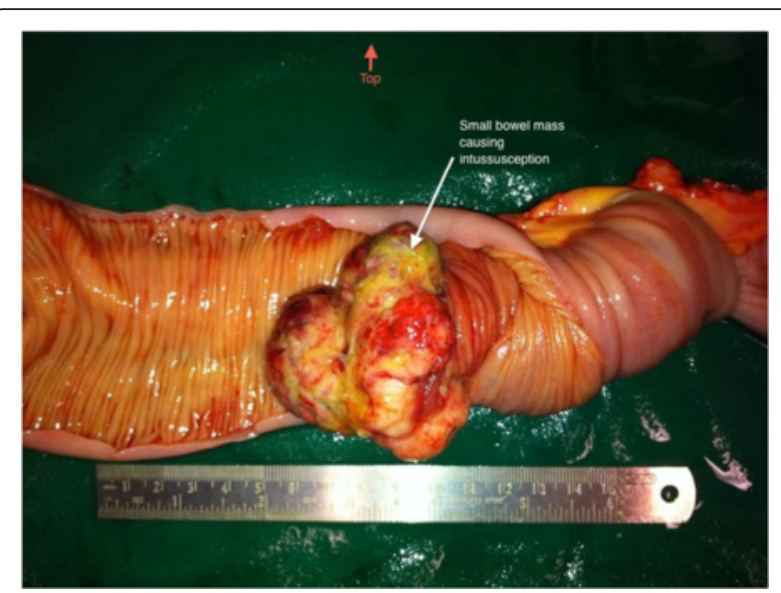

Fig. 7 Intraluminal mass forming pathologic lead point

Askin's tumor (Ewing sarcoma of the chest wall). ESFT tumours are of neural crest derivation that differentiate along a neuroendocrine lineage and are described as small round cell tumours. All ESFT tumours are characterized by a balanced chromosomal translocation between the $5^{\prime}$ half of the EWS gene (22q12) and the $3^{\prime}$ half of members of the ETS family of transcription factors, leading to the understanding that ESFT represents a single neoplastic entity [5].

Ewing sarcoma predominantly affects children and young adults with a peak incidence between 10 and 20 years of age. About $30 \%$ occur in adults over the age of 20 and fewer than $5 \%$ occur in adults over the age of 40 [6]. Ewing sarcoma most often arises in the mid-shaft or diaphysis of the long bones of the extremities with the spine making up only $8 \%$ of primary sites of Ewing sarcoma [2]. Our patient, being a 44-year-old female adult, did not fit the typical profile of an Ewing sarcoma patient and was initially treated as spinal metastases

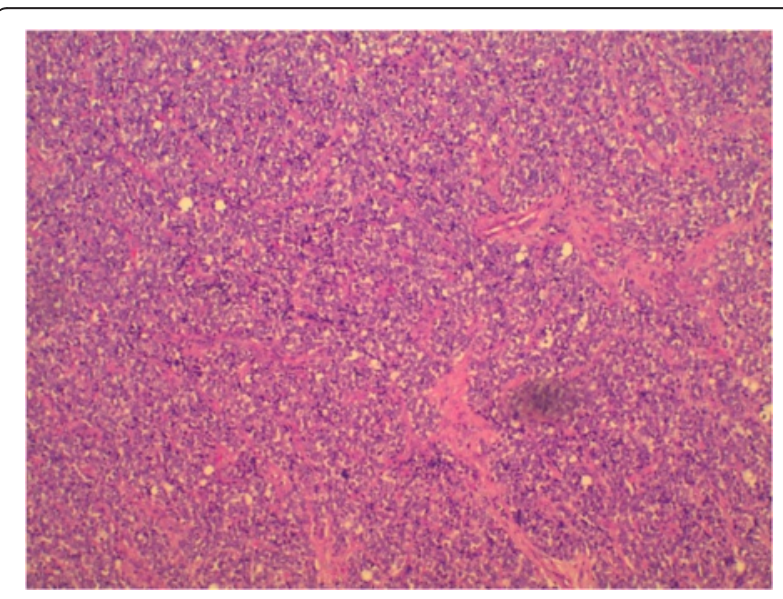

Fig. 8 Characteristic sheets of small blue round cells from primary vertebral Ewing sarcoma 


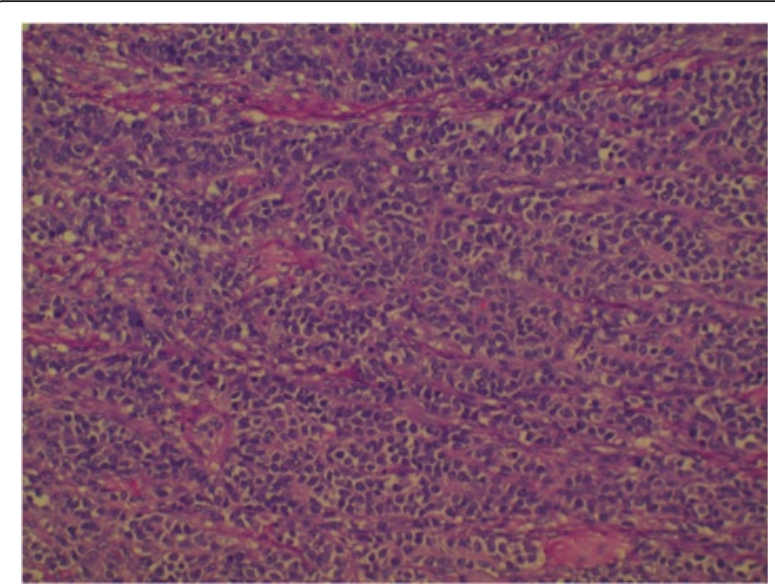

Fig. 9 Histomorphologically similar round cells from small bowel metastatic tumour

from a yet undetermined primary. It was only on histopathological examination of the spinal tumour that the diagnosis of Ewing sarcoma was reached.

The presence of metastasis is the single most important factor in determining survival in ESFT patients. Patients with metastatic disease at diagnosis have a dismal 5-year survival rate varying from $0-25 \%$, compared with $40-79 \%$ for those with localized disease [5, 7]. Chemotherapy is essential in the treatment of Ewing sarcoma because although approximately $80 \%$ of patients present with clinically localized disease, subclinical metastatic disease is presumed to be present in almost all patients due to a $80-90 \%$ relapse rate noted in patients who underwent local therapy alone [3]. It is possible that our patient had occult metastases that continued to rapidly progress after excision of the primary tumour before commencement of systemic chemotherapy. Metastases

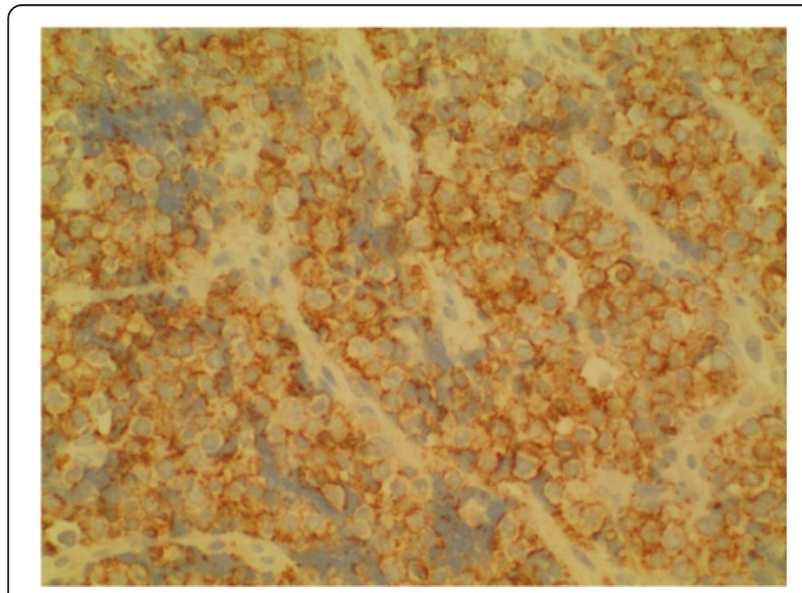

Fig. 10 Positive cell membrane reactivity for CD99 from primary vertebral Ewing sarcoma

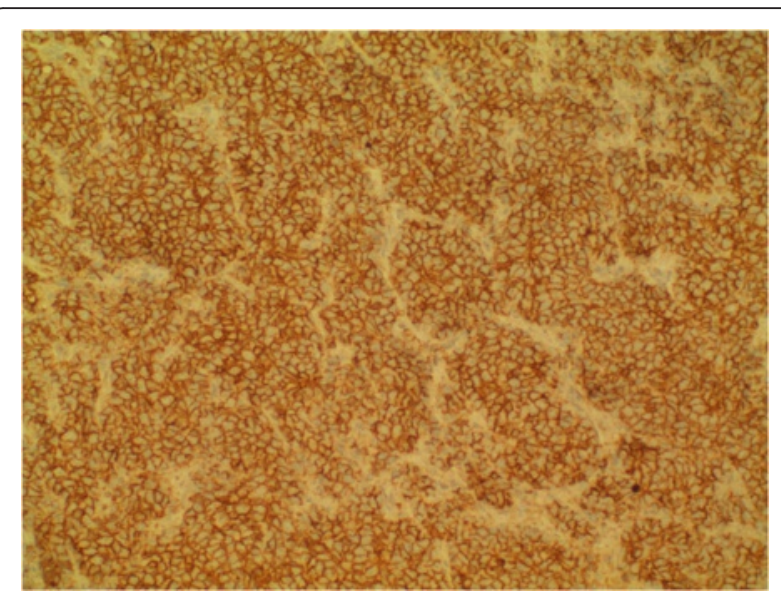

Fig. 11 Positive CD99 staining from small bowel metastatic tumour

are mostly found in the lungs (50\%), bone (25\%) and bone marrow (20\%) [4]. Only eight cases of primary Ewing sarcoma of the small bowel have been reported [8-10, 14, 15], and metastasis of Ewing sarcoma to the small bowel is even rarer with Capitini reporting a case of a 26-year-old male with metastasis of left femur Ewing sarcoma to the small bowel and brain following allogenic stem cell transplantation.

Intussusception is the invagination of a bowel loop with its mesenteric fold (intussusceptum) into the lumen of a contiguous portion of the bowel (intussuscipiens) as a result of peristalsis. Intussusception is rare in adults, accounting for $1-5 \%$ of all cases of intestinal obstruction and $5 \%$ of all intussusceptions [11]. Most cases of intussusception in adults are due to a pathologic lead point within the bowel and are malignant in over $50 \%$ of cases [12], thereby necessitating surgery and resection of the affected bowel segment. In the

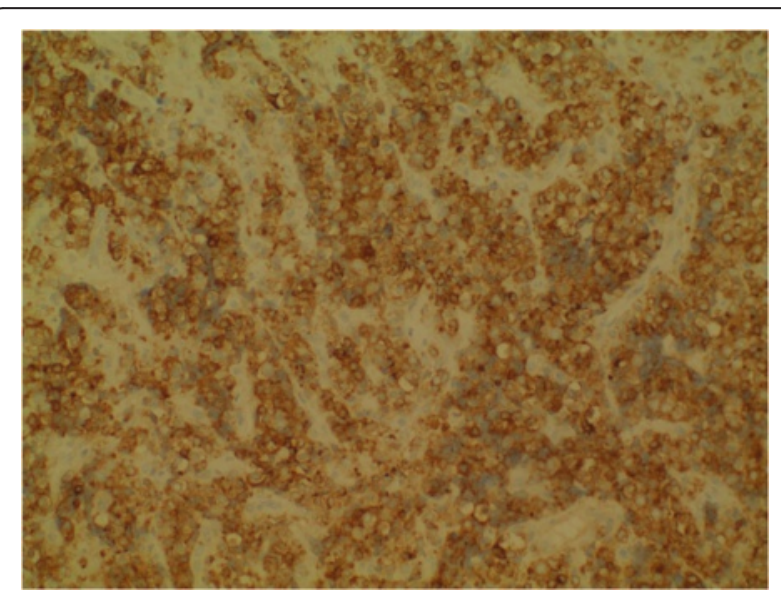

Fig. 12 Positive staining for neuroendocrine marker synaptophysin in primary vertebral Ewing sarcoma 


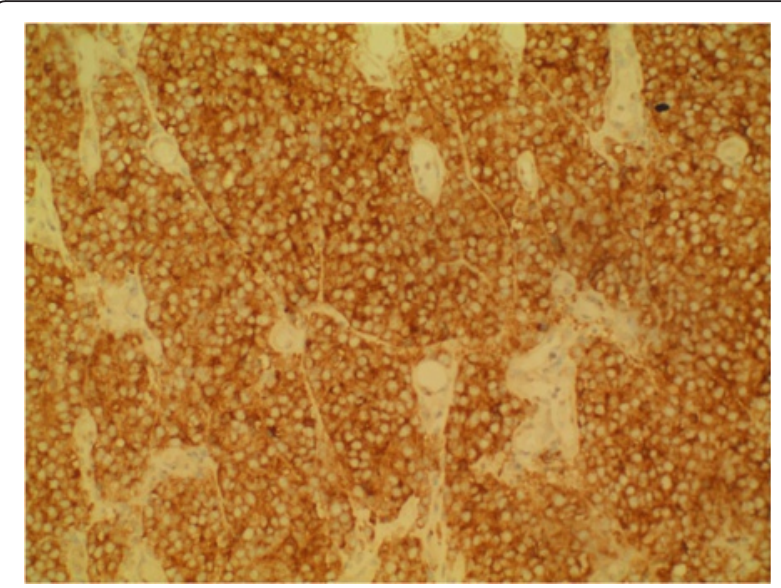

Fig. 13 Positivity of neural marker synaptophysin in small bowel metastatic tumour

small intestine, an intussusception can be secondary to the presence of intra- or extra-luminal lesions which include inflammatory lesions, Meckel's diverticulum, postoperative adhesions, lipoma, adenomatous polyps, lymphoma and metastases or iatrogenic (the presence of an intestinal tube, in patients with a gastrojejunostomy, etc.). Malignancy (adenocarcinoma) accounts for up to $30 \%$ of cases of intussusception occurring in the small bowel [11]. In 2003, Boehm [9] described a case of ileoileal intussusception in an 18-year-old male who presented with a protracted course of abdominal pain and vomiting for several weeks. The intussusception

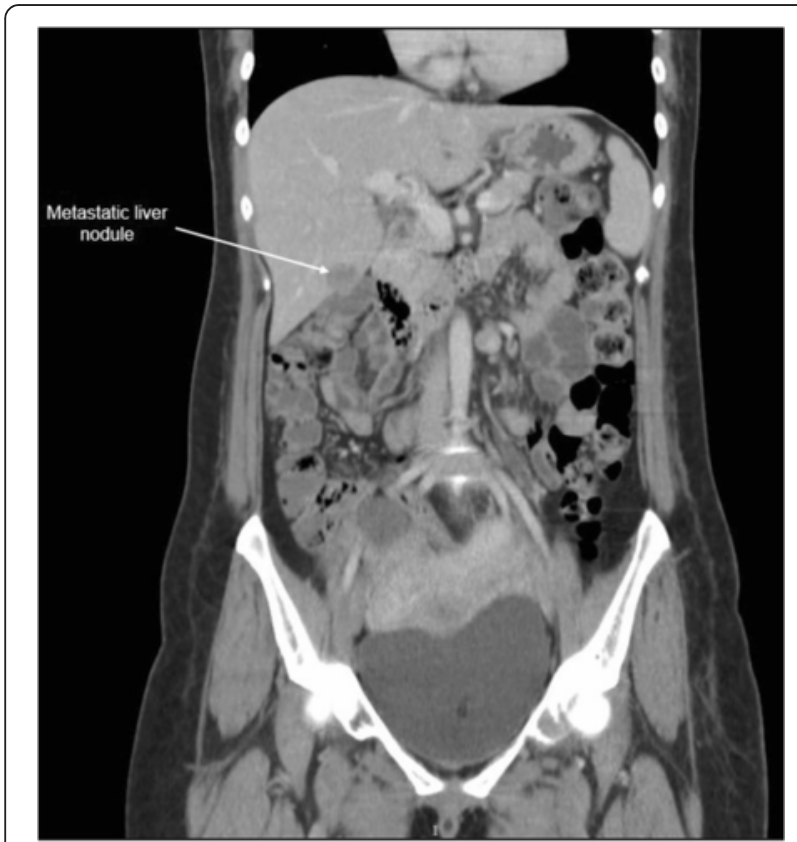

Fig. 14 Initial coronal CT showing normal appearance of bowel and liver metastasis

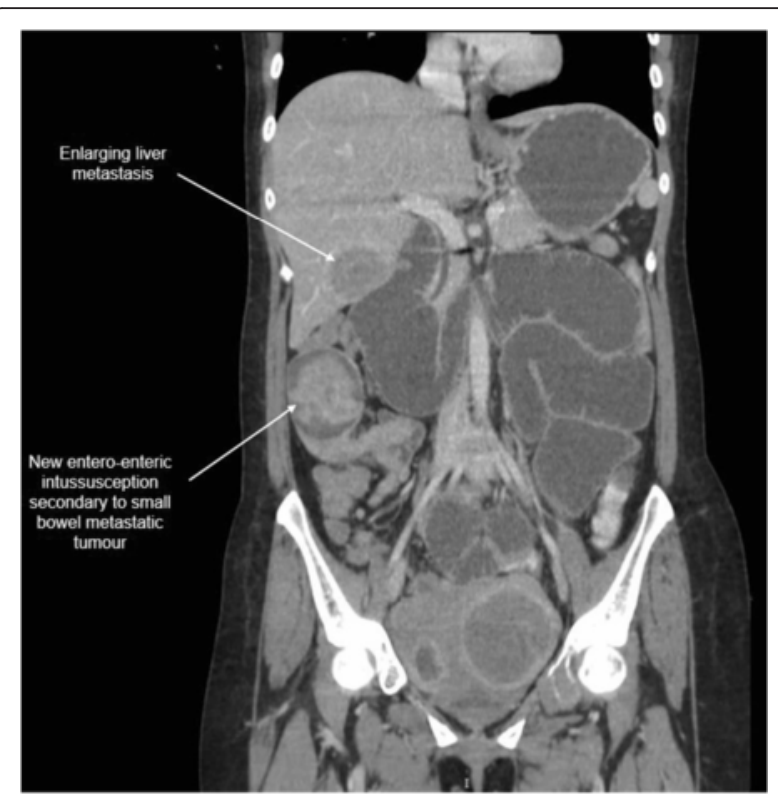

Fig. 15 Subsequent coronal CT showing new entero-enteric intussusception and enlargement of liver metastasis

was eventually discovered on laparotomy and histopathology of the resected bowel revealed primary Ewing sarcoma. Our patient suffered from intussusception as well, although the cause was due to a large jejunal intraluminal metastasis from her primary spinal ES. No bowel mass was evident on her initial CT scan (Figs. 3 and 14), but her subsequent $\mathrm{CT}$ performed after development of intestinal obstructive symptoms showed not only new development of small bowel intussusception but also progression of metastatic disease (Figs. 4, 5 and 15). The resected jejunal metastatic tumour, possibly a result of haematogenous spread, displayed the same histomorphological and immunohistochemical characteristics as the vertebral primary tumour (Figs. 8, 9, 10, 11, 12 and 13).

\section{Conclusions}

Ewing's sarcoma is a highly aggressive small round cell tumour that rarely arises in adults. The presence of metastases, overt or subclinical, is thought to be present in almost all patients at diagnosis and, as evidenced by our patient, can progress rapidly to cause further complications and confer a poorer survival. The possibility of metastasis, no matter how rare or unlikely the site is, should be considered and actively investigated to expedite treatment of the primary disease.

\section{Consent}

Written informed consent was obtained from the patient for the publication of this report and any accompanying images. A copy of the written consent is available for review by the Editor-in-Chief of this journal. 


\section{Competing interests}

The authors declare that they have no competing interests.

\section{Authors' contributions}

QTT and JYT performed the surgery. QTT obtained consent, performed the literature search and drafted the manuscript. SSA reviewed the histopathological slides. AYFC supervised the study and oversaw the care of the patient. JYT and AYFC proofread the paper. All authors read and approved the final manuscript.

\section{Author details}

'Department of General Surgery, Singapore General Hospital, Outram Road, Singapore 169608, Singapore. ${ }^{2}$ Department of Hepatopancreaticobiliary Surgery, Singapore General Hospital, Outram Road, Singapore 169608, Singapore. ${ }^{3}$ Department of Pathology, Singapore General Hospital, Outram Road, Singapore 169608, Singapore.

\section{Received: 6 February 2015 Accepted: 24 March 2016}

\section{Published online: 16 April 2016}

\section{References}

1. Hense HW, Ahrens S, Paulussen M, Lehnert M, Jurgens H. Factors associated with tumor volume and primary metastases in Ewing tumors: results from the El(CESS) studies. Ann Oncol. 1999;10(9):1073-7.

2. Cotterill SJ, Ahrens S, Paulussen M, Jurgens HF, Voute PA, Gadner H, Craft AW. Prognostic factors in Ewing's tumor of bone: analysis of 975 patients from the European Intergroup Cooperative Ewing's Sarcoma Study Group. J Clin Oncol. 2000;18(17):3108-14.

3. Nesbit Jr ME, Gehan EA, Burgert Jr EO, Vietti TJ, Cangir A, Tefft M, Evans R, Thomas P, Askin FB, Kissane JM, et al. Multimodal therapy for the management of primary, nonmetastatic Ewing's sarcoma of bone: a long-term follow-up of the First Intergroup study. J Clin Oncol. 1990;8(10):1664-74.

4. Balamuth NJ, Worner RB. Ewing's Sarcoma. Lancet Oncol. 2010;11:184-92.

5. Scurr M, Judson I. How to treat the Ewing's family of sarcomas in adult patients. Oncologist. 2006;11(1):65-72

6. Bacci G, Balladelli A, Forni C, Ferrari S, Longhi A, Bacchini P, Alberghini M, Fabbri N, Benassi M, Briccoli A, Picci P. Adjuvant and neoadjuvant chemotherapy for Ewing sarcoma family tumors in patients aged between 40 and 60: report of 35 cases and comparison of results with 586 younger patients treated with the same protocols in the same years. Cancer. 2007; 109(4):780

7. Seker MM, Kos T, Ozdemir N, Seker A, Aksoy S, Uncu D, Zengin N. Treatment and outcomes of Ewing Sarcoma in Turkish Adults: a single centre experience. Asian Pac J Cancer Prev. 2014;15(1):327-30.

8. Shek TW, Chan GC, Khong PL, Chung LP, Cheung AN. Ewing sarcoma of the small intestine. J Pediatr Hematol Oncol. 2001;23(8):530-2.

9. Boehm R, Till H, Landes J, Schmid I, Joppich I. Ileoileal intussusception caused by a Ewing sarcoma tumour. An unusual case report. Eur J Pediatr Surg. 2003:13:272-5.

10. Milione M, Gasparini P, Sozzi G, Mazzaferro V, Ferrari A, Casali PG, Perrone F, Tamborini E, Pellegrinelli A, Gherardi G, Arrigoni G, Collini P, Testi A, De Paoli E, Aiello A, Pilotti S, Pelosi G. Ewing sarcoma of the small bowel: a study of seven cases, including one with the uncommonly reported EWSR1-FEV translocation. Histopathology. 2014;64:1014-26.

11. Marinis A, Yiallourou A, Samanides L, Dafnios N, Anastasopoulos G, Vassiliou I, et al. Intussusception of the bowel in adults: a review. World J Gastroenterol. 2009;15(4):407-11.

12. Eisen LK, Cunningham JD, Aufses Jr AH. Intussusception in adults: institutional review. J Am Coll Surg. 1999;188(4):390-5.

13. Capitini CM, Derdak J, Hughes MS, Love CP, Baird K, Mackall CL, Fry TJ. Unusual sites of extraskeletal metastases of Ewing sarcoma after allogeneic hematopoietic stem cell transplantation. J Pediatr Hematol Oncol. 2009; 31(2):142-4

14. Adair A, Harris SA, Coppen MJ, Hurley PR. Extraskeletal Ewings sarcoma of the small bowel: case report and literature review. J R Coll Surg Edinb. 2001; 46(6):372-4.

15. Batziou C, Stathopoulos GP, Petraki K, Papadimitriou C, Rigatos SK Kondopodis E. Primitive neurectodermal tumors: a case of extraosseous Ewing's sarcoma of the small intestine and review of the literature. J BUON. 2006;11(4):519-22

\section{Submit your next manuscript to BioMed Central and we will help you at every step:}

- We accept pre-submission inquiries

- Our selector tool helps you to find the most relevant journal

- We provide round the clock customer support

- Convenient online submission

- Thorough peer review

- Inclusion in PubMed and all major indexing services

- Maximum visibility for your research

Submit your manuscript at www.biomedcentral.com/submit 